REVIEW

\title{
Hip arthroscopy: current concepts and review of literature
}

\author{
Vijay D Shetty, Richard N Villar
}

Br J Sports Med 2007;41:64-68. doi: 10.1136/bjsm.2006.027755

Diagnosis and treatment of intra-articular hip problems in young patients present a challenge to hip surgeons. Previous studies have shown that non-invasive investigations such as radiography, computed tomography and magnetic resonance imaging provide limited help. Non-operative treatment is likely to result in persistent symptoms, and surgical options for intraarticular hip problems involve open arthrotomy of the hip joint, which carries potential risks associated with joint dislocation. Arthroscopy of the hip joint, therefore, seems to be an attractive option. It was once thought that introduction of a straight arthroscope into the ball-and-socket hip joint was almost impossible. Hip arthroscopy has seen several advances since then, and the speed at which it developed in recent years directly corresponded to the rate at which the conditions affecting the hip joint were identified. Athletes and other young individuals with hip injuries are increasingly being diagnosed with an ever evolving series of conditions. Many of these conditions were previously unrecognised and thus left untreated, resulting in premature ends to the patients' competitive careers. Hip arthroscopy, as with any procedure, is not without risks. The procedure is not widely available as it requires specialist equipment and takes a long time to learn. Complications are few, occurring in $<5 \%$ of patients.

See end of article for authors' affiliations

Correspondence to: Vijay D Shetty, LH Hiranandani Hospital, Powai, Mumbai 400076, India; vijay@vijaydshetty. com

Accepted 28 August 2006 Published Online First 29 November 2006
D iagnosis and treatment of intra-articular hip problems in young patients present a challenge. Historically, there have been limited diagnostic and treatment options available for diseases that affect the cartilage, bone or synovium in the young hip joint. Provocative manoeuvres to diagnose a hip problem are unreliable owing to extreme apprehension, and non-invasive investigations provide limited help with the diagnosis of these conditions. Radiographs have traditionally been poor at detecting early lesions in the hip. Other imaging studies have not been very reliable either, as a negative imaging study does not exclude important intra-articular pathologies. ${ }^{1}$ Although gadolinium-enhanced magnetic resonance imaging (MRI) is much more sensitive than conventional MRI for detecting intra-articular lesions, ${ }^{2}$ limitations do exist with these investigations, as previous studies have shown. ${ }^{34}$ Diagnostic hip blocks are useful to distinguish between intra-articular and extra-articular lesions, ${ }^{5}$ but they provide information on the generality of intra-articular problems rather than specific lesions within the ball-and-socket joint.

Although open surgeries of the hip joint are performed more routinely and successfully, they are not without potential risks associated with joint dislocation, infection, deep vein thrombosis, avascular necrosis, major nerve or vessel injury, heterotopic bone and muscle weakness. ${ }^{6-8}$ Nonoperative treatment is likely to result in persistent symptoms. Keyhole surgery of the hip joint, therefore, seems to be an attractive option.

It was once thought that the introduction of an arthroscope into a hip joint was almost impossible. In 1931, Burman" stated that "It is manifestly impossible to insert a needle between the head of the femur and the acetabulum". Hip arthroscopy has seen several advances since then. The speed at which it developed in recent years directly corresponded to the rate at which the conditions affecting the hip joint were identified. The advent of hip arthroscopy has facilitated comprehensive access to an evolving series of conditions that affect the hip joint, many of which were previously unrecognised and thus left untreated. ${ }^{10}$ Today, arthroscopy of the hip joint has led to a greater understanding of the nature of adolescent and adult hip pathologies of acetabular labrum, acetabular chondral surfaces, fovea, ligamentum teres, femoral head and adjacent synovium, ${ }^{5}$ and their management, particularly in hip injuries in athletes.

Having been used minimally in the 1980s, hip arthroscopy has a recent history. Our understanding of arthroscopic anatomy, indications, potential complications and techniques has evolved in recent years, and hip arthroscopy has become a successful treatment method for a variety of hip pathologies in selected patients. It is hoped that this article will shed light on the most recent concepts and developments in this ever evolving technique.

\section{TECHNIQUE}

Preoperative planning is important for hip arthroscopy. The range of movement of the hip must be assessed to determine the presence of fixed deformities. Radiographs should be completed to identify spurs or dysplasia. Entry into the joint may become difficult if there are large spurs, and dysplastic hips have been shown to have poorer outcomes.

In our institution, hip arthroscopy is performed in the lateral position with the patient under general anaesthesia, under image intensifier control and traction (figl). In some centres, the procedure is performed with the patient in the supine position. ${ }^{11}$ We believe that the lateral position provides enhanced instrument manoeuvrability, easier entry

Abbreviations: FAl, femoroacetabular impingement; MRI, magnetic resonance imaging 


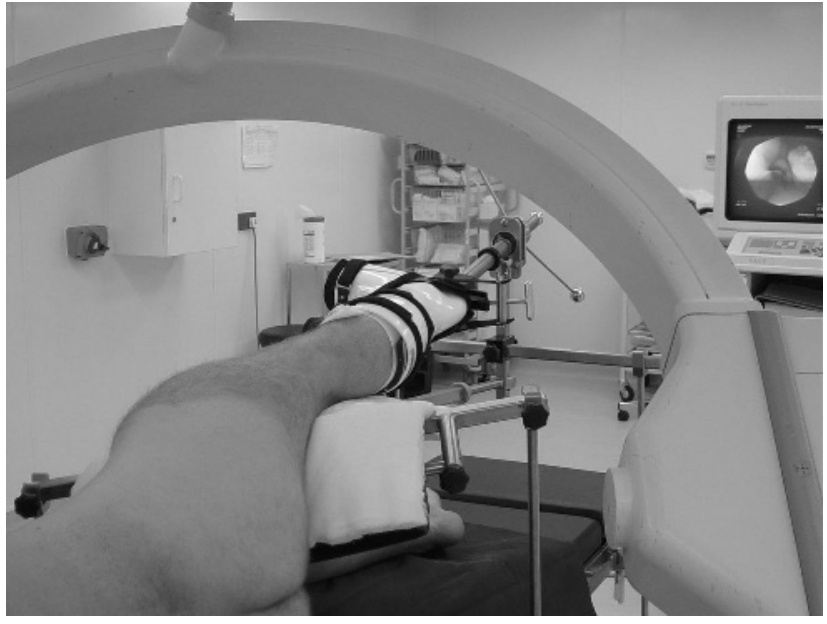

Figure 1 Lateral position for right hip arthroscopy.

into the hip joint and particularly helps in obese patients, as fatty tissue tends to fall out of the way. The traction apparatus includes a foot piece and a stretcher to hold the leg, a well-padded perineal post for counter traction, and a tensiometer to gauge the amount of traction applied (fig 1).

The lower limb is placed in slight flexion (approximately $10-20^{\circ}$ ), with the foot maintained in neutral to slight external rotation. The perineal post is pushed upwards against the medial portion of the thigh on the involved leg, keeping the post away from the branch of the pudendal nerve that crosses over the pubic ramus. Distraction is achieved carefully until the "vacuum phenomenon" is seen on the image intensifier, as described by Byrd. ${ }^{11}$ Usually, three portals are used: anterolateral, proximal trochanteric and posterolateral, although sometimes more portals may be required. One needs to be extremely careful of the lateral cutaneous nerve when establishing the anterolateral portal and of the posterior neurovascular bundle when establishing the posterolateral portal. Specially designed extra-long arthroscopic instruments, which include a long spinal needle (Howard Jones spinal needle with Pitkin point, Luer lock fitting, $15 \mathrm{~g}$ and $155 \mathrm{~mm}$ in length, Smith and Nephew, Massachusetts, USA) and a specially designed flexible guide wire to reach the depth of the hip joint, are used. Special attention must be taken to avoid penetration

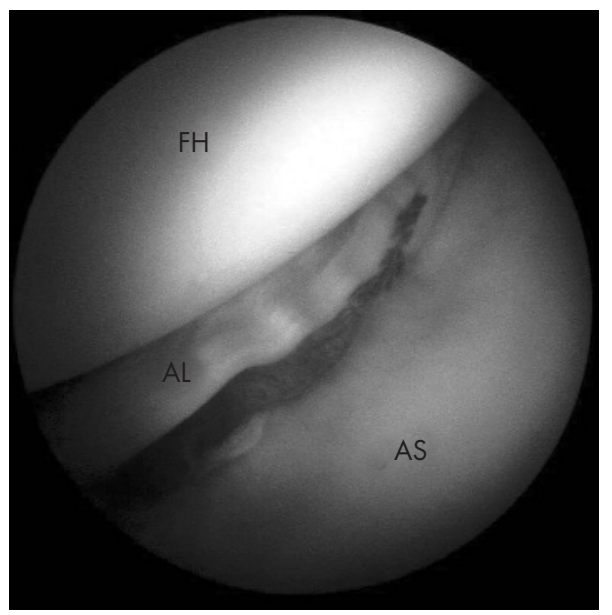

Figure 2 A peripheral tear of the acetabular labrum. AL, acetabular labrum; AS, acetabular surface; FH, femoral head. of the acetabular labrum. As the needle penetrates through the capsule, there is a palpable decrease in resistance. If the needle is directed into the labrum, the resistance is greater. The joint is then distended with approximately $40 \mathrm{~cm}^{3}$ of saline, and the intracapsular position of the needle confirmed by backflow of fluid. A guide wire is fed through the spinal needle into the joint space, and the spinal needle is removed. After the guide wire is positioned in the joint, a sharp cannulated trocar is used to penetrate only the joint capsule, followed by a blunt cannulated trocar, to avoid damage to the articular cartilage.

Understanding the arthroscopic anatomy of the hip joint is essential before embarking on hip arthroscopy. During the procedure, the hip joint is systematically inspected so as to view every possible part and detect any abnormalities. An arthroscopic pump is used throughout to maintain constant distension of the joint with saline solution. A $70^{\circ}$ arthroscope is used most commonly for hip arthroscopy, although a $30^{\circ}$ arthroscope is also useful. Most hip arthroscopy procedures require the use of multiple portals for the proper positioning of hand instruments, power shavers and electrocautery devices. At the end of the procedure, traction is removed carefully under the direct supervision of the operating surgeon. The average imaging time in our institution is $10 \mathrm{~s}$ and the procedure takes roughly $40 \mathrm{~min}$.

\section{FINDINGS AT HIP ARTHROSCOPY \\ Acetabular labral injuries}

Previous reports have suggested that injuries of the acetabular labrum (fig 2) are mostly due to degenerative change in the hip $(50 \%)$ or trauma $(20 \%) .{ }^{12-15}$ When the damaged labral cartilage is subjected to repetitive loading conditions, joint fluid is pumped beneath the acetabular chondral cartilage, causing delamination (fig 3 ) of the articular cartilage. ${ }^{15}$ As a result, the fluid eventually burrows beneath the subchondral bone to form a subchondral cyst. ${ }^{15}$ Traumatic acetabular labral injuries commonly occur in the presence of abnormal proximal femoral or acetabular anatomy, ${ }^{16}$ or during abnormal loading, as may be seen in the hips of professional sportsmen. ${ }^{17}{ }^{18}$ Studies have shown that most labral injuries occur at the anterior marginal attachment of the acetabulum, ${ }^{18}{ }^{19}$ although injury to the posterosuperior aspect of the labrum has been reported in an adolescent Asian population by Ikeda et al. ${ }^{20}$ Often, injuries of the acetabular labrum are associated with congenital or structural abnormalities such as acetabular dysplasia, slipped

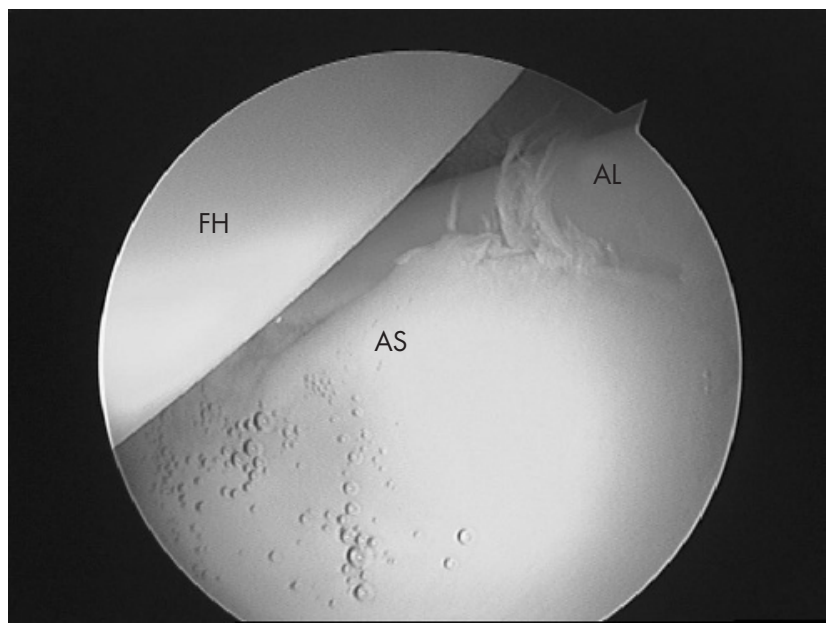

Figure 3 Clear delamination of the acetabular articular cartilage from the subchondral bone. AL, acetabular labrum; AS, acetabular surface (delaminated); $\mathrm{FH}$, femoral head. 


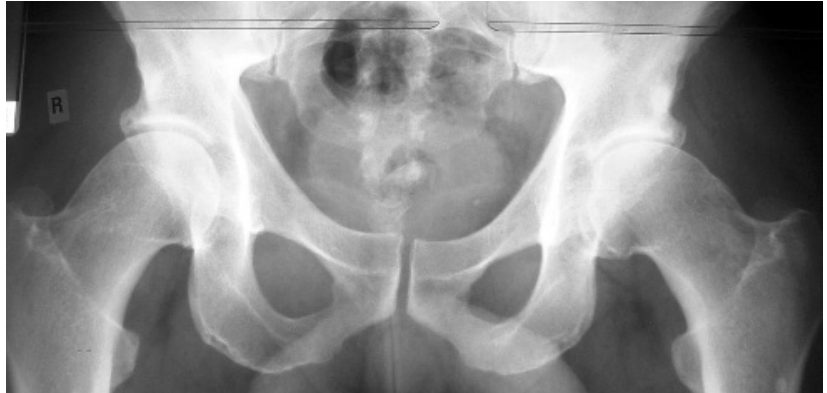

Figure 4 Plain $x$ ray of pelvis showing "pistol grip deformity" of both proximal femora. If the $x$ ray is shown upside down, the proximal femora appear like pistol grips.

upper femoral epiphysis or Perthes' disease. ${ }^{21}$ Studies have also shown that labral tears are linked to the onset of hip impingement, now termed "femoroacetabular impingement" (FAI). ${ }^{152-24}$

\section{Femoroacetabular impingement}

A difficult entity to diagnose and treat, hip impingement usually appears in younger and more physically active adults and can be physically debilitating. Ganz et al ${ }^{22}$ described two distinctive types of FAI. "Pincer impingement" occurs as a result of anterior overcoverage of the acetabulum or acetabular retroversion, and "cam impingement" occurs when a nonspherical femoral head abuts against the anterior acetabulum, usually with the hip in flexion. A non-spherical femoral head is known to occur because of structural proximal femoral headneck offset abnormalities, usually described as "pistol grip deformity" (fig 4) of the femoral neck, ${ }^{25}$ attributed to mild or subclinical slipped upper femoral epiphysis. ${ }^{26}$ Several other morphological deviations in the hip can also lead to FAI, as described by Ito et al. ${ }^{27}$ FAI results in repetitive microtrauma to the acetabular labrum at the extremes of motion of the hip, leading to labral and chondral lesions, known to have a role in the cascade of hip osteoarthritis. ${ }^{27}$ Arthroscopic assessment and removal of the impingement lesion, either by partial labrectomy or by debridement of non-spherical femoral heads with decreased head-neck offset causing impingement, restores hip mechanics at the extremes of motion. ${ }^{28}$ This results in elimination of the microtrauma to the anterior acetabular

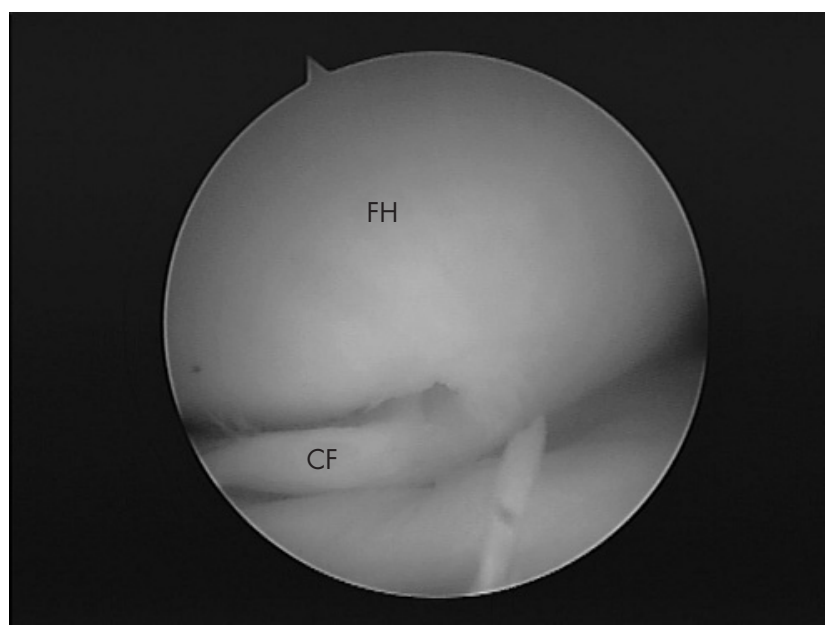

Figure 5 Chondral flap lesion in the femoral head. CF, chondral flap; FH, femoral head.

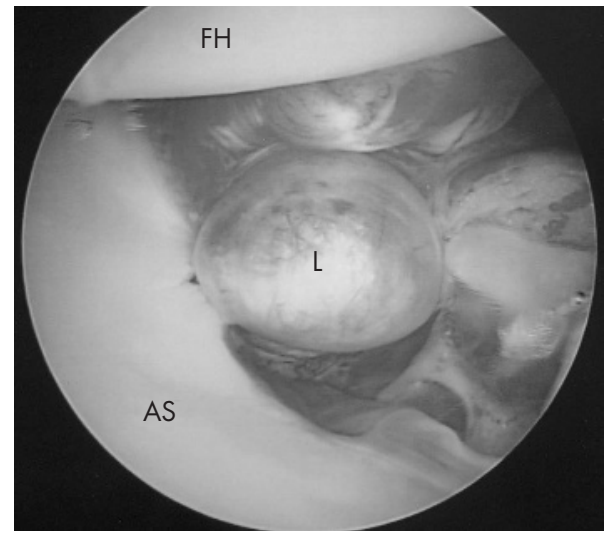

Figure 6 Lipoma (L) in the cotyloid fossa. It is difficult to pick up these abnormalities by conventional investigations. AS, acetabular surface; $F H$, femoral head.

margin and, thus, potentially slows down the progression of osteoarthritis in young individuals. ${ }^{29}$

\section{Chondral lesions}

The earliest chondral lesion detectable at hip arthroscopy is chondral split, progressing onwards to a more formal delamination, chondral flap lesion and subchondral cyst. ${ }^{15}$ The diagnosis of these chondral lesions (fig 5) is extremely difficult with the available non-invasive techniques. Chondral flaps and osteochondral defects may occur in association with a multitude of hip conditions. The anterior aspect of the acetabulum is a commonly involved site, as shown by McCarthy and Lee ${ }^{5}$ in 2001. They found that 259 of 477 (54\%) chondral injuries had occurred in the anterior aspect of the acetabulum in their series. ${ }^{15}$ Early chondral splits are usually "glued" using a radiofrequency probe, whereas large, unstable flaps are excised and the underlyingsubchondral bone microfractured. The outcome of treatment for these lesions depends mainly on how soon the diagnosis is made and the extent of damage.

\section{Less common findings in hip arthroscopy}

Other less common pathological conditions diagnosed at hip arthroscopy include avascular necrosis, loose bodies, lesions of the synovium, abnormalities in the cotyloid fossa (fig 6) and torn ligamentum teres. The role of arthroscopy in avascular necrosis is largely diagnostic. Hip arthroscopy helps to stage the disease $^{30}$ and detect osteochondral degeneration, which cannot

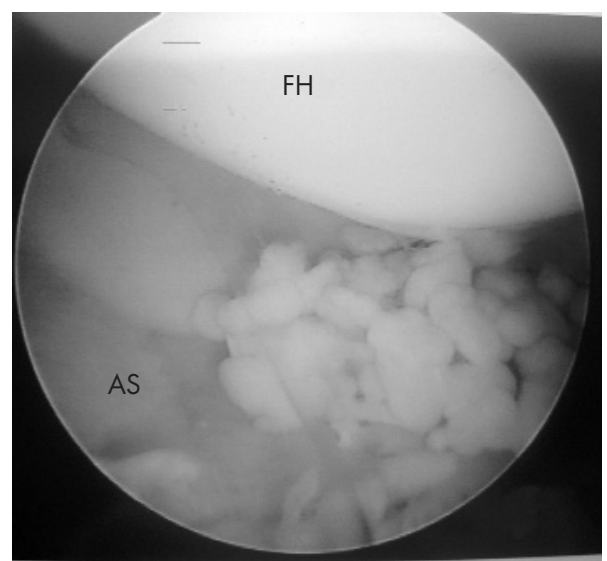

Figure 7 Synovial chondromatosis of the hip with numerous loose bodies. AS, acetabular surface; $\mathrm{FH}$, femoral head. 


\section{What is already known on this topic}

- It was once thought that hip arthroscopy was almost impossible to perform.

- The late 1990s and early 2000s saw an increasing number of procedures being performed worldwide.

- This has led to the recognition of a number of conditions that were previously undiagnosed and, therefore, left untreated.

- The speed at which hip arthroscopy developed in the recent years directly corresponded to the rate at which the conditions affecting the hip joint were identified.

be identified by plain radiographs and MRI, particularly in post-collapse femoral heads. ${ }^{31}$ Occasionally, arthroscopy may help to relieve mechanical symptoms in avascular necrosis. ${ }^{532}$ Synovial chondromatosis (fig 7) produces loose bodies in the hip, and hip arthroscopy helps to remove these loose bodies less invasively, ${ }^{33}$ although a recurrence rate of $10 \%$ has been reported in patients with synovial chondromatosis treated with hip arthroscopy. ${ }^{5}$ Lesions of the ligamentum teres, as a source of hip pain, either alone or in conjunction with other articular lesions, have been described by Gray and Villar ${ }^{34}$ and recently, by Byrd and Jones. ${ }^{35}$ These lesions are thought to be associated with trauma, dysplasia or degenerative arthritis.

\section{INDICATIONS FOR HIP ARTHROSCOPY}

The difficulty in diagnosing all the above lesions with conventional methods and in determining their effect on outcome provides a substantial rationale for hip arthroscopy. ${ }^{5}$ Current indications for hip arthroscopy include the presence of symptomatic acetabular labral tears, femoroacetabular impingement, chondral lesions, osteochondritis dissecans, ligamentum teres injuries, snapping hip syndrome, iliopsoas bursitis and loose bodies. Less common indications include management of osteonecrosis of the femoral head, synovial abnormalities, crystalline hip arthropathy (gout and pseudogout), infection and posttraumatic intra-articular debris. In rare cases, hip arthroscopy can be used to temporise the symptoms of mild-to-moderate hip osteoarthritis with associated mechanical symptoms. ${ }^{10}$ Patient selection is an important issue for a potentially successful outcome. General parameters include younger patients, mechanical joint symptoms, partial joint space preservation, adequate rotational motion, failure of conservative treatment, and reasonable expectations from the patient. ${ }^{36}$ Arthroscopic evaluation may also be considered when joint symptoms are unremitting, and no diagnosis has been made. If the symptoms have been present for $>6$ months, one can expect an arthroscopy-facilitated diagnosis in approximately $40 \%$ of these patients. ${ }^{37}$

Conditions that limit the potential for hip distraction may preclude arthroscopy. These include joint ankylosis, dense heterotopic bone formation, considerable protrusion and morbid obesity, not only because of distraction limitations but also because of the requisite length of instruments necessary to access and manoeuvre within the deeply receded joint. In addition, sepsis with accompanying osteomyelitis or abscess formation requires open surgery.

\section{PROBLEMS WITH HIP ARTHROSCOPY}

Hip arthroscopy is technically demanding owing to both anatomical and technical constraints, and involves a steep learning curve. ${ }^{5}$ The hip joint is deeply recessed in a soft-tissue envelope and the femoral head is contained in a concavely shaped acetabulum. $^{38}$ The joint capsule, especially the iliofemoral ligament, is thick and resists traction for joint distraction.
What this study adds

- Hip arthroscopy is not just about diagnosis.

- Recent advances in the techniques of hip arthroscopy have allowed surgeons to treat conditions such as femoroacetabular impingement with minimal access to the joint.

- Athletes and other young individuals with hip injuries are increasingly being diagnosed with an ever evolving series of conditions. Many of these conditions were previously unrecognised, resulting in premature ends to the patients' competitive careers.

- With current technical advancement, it remains to be seen whether we can change the natural history of the disease process and potentially curb the progression of osteoarthritis.

Sufficient joint distraction is paramount, and Byrd et al ${ }^{39}$ described a vacuum phenomenon that occurs after the initial application of traction. The magnitude of the force required to provide sufficient distraction has been reported to be between 300 and $900 \mathrm{~N}$ in an anaesthetised patient. ${ }^{40}$ Guhl et $a l^{41}$ and Glick et $\mathrm{al}^{42}$ suggested that a longitudinal force of at least $20 \mathrm{~kg}$ may be required to obtain a good view of the joint. With increased traction, neurovascular structures are susceptible to injury leading to complications. ${ }^{43}$

Complications occur in $0.5-5 \%$ of patients and are most often related to transient neuropraxia due to distraction of the joint. ${ }^{4-46}$ Injuries to the sciatic nerve (posterior portal), lateral femoral cutaneous nerve (anterolateral portal) and pudendal nerves have been reported in the literature. ${ }^{42} 4748$ However, the effects of traction on the integrity of the joint capsule, the ligamentum teres and the acetabular labrum remain unknown. Some authors argue that the labrum may be vulnerable to relatively minor trauma by traction, ${ }^{47}{ }^{49}$ but a study by Elsaidi $e t$ $a l^{50}$ did not show any injury to the acetabular labrum from longitudinal distraction of the hip on the fracture table.

\section{CONCLUSIONS}

Historically, athletes and other young individuals with hip injuries were simply resigned to living within the constraints of their symptoms, being diagnosed with an ill-defined chronic groin injury and often prematurely ending their competitive careers. ${ }^{51}$ Advances in hip arthroscopic techniques have helped us to understand various forms of intra-articular hip pathologies and to define elusive causes of disabling hip pain in athletic population, including occult labral and chondral damage and rupture of ligamentum teres. Acetabular labral tears can contribute to persistent symptoms in the hip joint, and lesions of the articular cartilage of the femoral head and acetabulum can eventually contribute to the progression of hip osteoarthritis. We are now capable of recognising these at an early stage in the disease. However, with current technical advancement, it remains to be seen whether we can change the natural history of the disease process and potentially curb the progression of osteoarthritis.

\section{ACKNOWLEDGEMENT}

We thank Mr Vikas Khanduja from Cambridge Hip and Knee Unit for helping with fig 1

\section{Authors' affiliations}

Vijay D Shetty, LH Hiranandani Hospital, Mumbai, India

Richard N Villar, Cambridge Hip and Knee Unit, Cambridge, UK

Competing interests: None declared. 


\section{REFERENCES}

1 Walton NP, Jahromi I, Lewis PL. Chondral degeneration and therapeutic hip arthroscopy. Int Orthop 2004;28:354-6.

2 McCarthy JC, Busconi B. The role of hip arthroscopy in the diagnosis of hip disease. Orthopedics 1995; 18:753-6.

3 Duffy DJ, Wall O, Macdonald DA. A comparison of magnetic resonance imaging and arthroscopic diagnosis of hip disorders. J Bone Joint Surg [Br] 2004;86(Suppl I):73

4 Baber YF, Robinson AHN, Villar RN. Is diagnostic arthroscopy of the hip worthwhile? A prospective review of 328 adults investigated for hip pain. J Bone Joint Surg [Br] 1999:81:600-3.

5 McCarthy JC, Lee JA. Hip arthroscopy: indications, outcomes, and complications. $J$ Bone Joint Surg [Am] 2005;87: 1 138-45

6 Amstutz HC, Maki S. Complications of trochanteric osteotomy in total hip replacement. J Bone Joint Surg [Am] 1978;60:214-16.

7 Dahl OE, Gudmundsen TE, Haukeland L. Late occurring clinical deep vein thrombosis in joint-operated patients. Acta Orthop Scand 2000;71:47-50.

8 Haake DA, Berkman SA. Venous thromboembolic disease after hip surgery. Risk factors, prophylaxis, and diagnosis. Clin Orthop 1989;242:212-31.

9 Burman MS. Arthroscopy or the direct visualization of joints: an experimental cadaver study. J Bone Joint Surg 1931;29:669-95.

10 McCarthy JC. The role of hip arthroscopy: useful adjunct or devil's tool? Orthopaedics 2002;25:947-8.

11 Byrd JW. Hip arthroscopy. The supine position. Clin Sports Med 2001;20:703-31.

12 Lage LA, Patel JV, Villar RN. The acetabular labral tear:an arthroscopic classification. Arthroscopy 1996;12:269-72.

13 Leunig $M$, Beck M, Woo A, et al. Acetabular rim degeneration: a constant finding in the aged hip. Clin Orthop 2003:413:201-7.

14 Seldes RM, Tan V, Hunt J, et al. Anatomy, histologic features, and vascularity of the adult acetabular labrum. Clin Orthop 2001;382:232-40.

15 McCarthy JC, Noble PC, Schuck MR, et al. The Otto E. Autofranc Award: the role of labral lesions to development of early hip disease, Clin Orthop 2001;393:25-37.

16 McCarthy JC, Lee JA. Acetabular dysplasia: a paradigm of arthroscopic examination of chondral injuries. Clin Orthop 2002:405:122-8.

17 McCarthy J, Barsoum W, Puri L, et al. The role of hip arthroscopy in the elite athlete. Clin Orthop 2003;406:71-4.

18 Fitzgerald RH Jr. Acetabular labrum tears. Diagnosis and treatment. Clin Orthop 1995:311:60-8.

19 McCarthy JC, Noble PC, Schuck MR, et al. The watershed labral lesion: its relationship to early arthritis of the hip. J Arthroplasty 2001;16(Suppl 1):81-7.

20 Ikeda T, Awaya G, Suzuki S, et al. Torn acetabular labrum in young patients. Arthroscopic diagnosis and management. J Bone Joint Surg [Br] 1998:70:13-16.

21 Wenger DE, Kendell KR, Miner MR, et al. Acetabular labral tears rarely occur in the absence of bony abnormalities. Clin Orthop 2004;426:45-50

22 Ganz R, Parvizi J, Beck $M$, et al. Femoroacetabular impingement: a cause for osteoarthritis of the hip. Clin Orthop 2003;417:112-20.

23 Lavigne $M$, Parvizi J, Beck $M$, et al. Anterior femoroacetabular impingement, I: technique of joint preserving surgery. Clin Orthop 2004;413:61-6.

24 Tanzer M, Noiseux N. Osseous abnormalities and early osteoarthritis: the role of hip impingement. Clin Orthop 2004;429:170-7.

25 Klaue K, Durnin C, Ganz R. The acetabular rim syndrome. A clinical presentation of dysplasia of the hip. J Bone Joint Surg [Br] 1991;73:423-9

26 Goodman DA, Feighan JE, Smith AD, et al. Subclinical slipped capital femoral epiphysis. Relationship to osteoarthritis of the hip. J Bone Joint Surg [Am] 1997; 79: 1489-97.

27 Ito $K$, Minka MA, Leunig M, et al. Femoroacetabular impingement and the cameffect. A MRI-based quantitative anatomical study of the femoral head-neck offset. J Bone Joint Surg [Br] 2001;83:171-6.

28 Crawford JR, Villar RN. Current concept in the management of femoroacetabular impingement. J Bone Joint Surg [Br] 2005;87:1459-62.

29 Bare AA, Guanche CA. Hip impingement: the role of arthroscopy. Orthopedics 2005;28:266

30 Sekiya JK, Ruch DS, Hunter DM, et al. Hip arthroscopy in staging avascular necrosis of the femoral head. J South Orthop Assoc 2000;9:254-61.

31 Ruch DS, Sekiya J, Dickson-Schaefer W, et al. The role of hip arthroscopy in evaluation of avascular necrosis. Orthopedics 2001:24:339-43.

32 McCarthy J, Puri L, Barsoum W, et al. Articular cartilage changes in avascula necrosis: an arthroscopic evaluation. Clin Orthop 2003;406:64-70.

33 Krebs VE. The role of hip arthroscopy in the treatment of synovial disorders and loose bodies. Clin Orthop 2003;406:48-59.
34 Gray AJ, Villar RN. The ligamentum teres of the hip: an arthroscopic classification of its pathology. Arthroscopy 1997;13:575-8.

35 Byrd JWT, Jones KS. Traumatic rupture of the ligamentum teres as a source of hip pain. Arthroscopy 2004;20:385-91.

36 Byrd JWT. Hip arthroscopy: it's role in osteoarthritis. J Bone Joint Surg [Br] 2004;86:207.

37 Villar RN. Hip arthroscopy. Br J Hosp Med 1992;47:763-6.

38 Monllau JC, Solano A, León A, et al. Tomographic study of the arthroscopic approaches to the hip joint. Arthroscopy 2003;19:368-72.

39 Byrd JWT, Pappas JN, Pedley MJ. Hip arthroscopy an anatomic study of portal placement and relationship to the extra-articular structures. Arthroscopy 1995; 11:418-23.

40 Blitzer CM. Arthroscopic management of septic arthritis of the hip. Arthroscopy 1993;9:414-16.

41 Guhl JF, Oldon DW, Sprague NF. Specific complications: elbow, wrist, hip, and ankle. In: Sprague NF III, eds. Complications in arthroscopy. New York: Raven Press, 1989:199-223.

42 Glick JM, Sampson TG, Gordon RB, et al. Hip arthroscopy by the latera approach. Arthroscopy 1987;31:4-12.

43 Dorfmann H, Boyer T. Hip arthroscopy utilizing the supine position. Arthroscopy 1996;12:264-7.

44 Clarke MT, Arora A, Villar RN. Hip arthroscopy: complications in 1054 cases. Clin Orthop 2003;406:84-8.

45 Griffin DR, Villar RN. Complications of arthroscopy of the hip. J Bone Joint Surg [Br] 1999;81:604-6.

46 Sampson TG. Complications of hip arthroscopy. Clin Sports Med 2001;20:831-5.

47 Fitzgerald RH Jr. Acetabular labrum tears: diagnosis and treatment. Clin Orthop 1995:311:60-8.

48 Rodeo SA, Forster RA, Weiland AJ. Neurological complications due to arthroscopy. J Bone Joint Surg [Am] 1993;75:917-26.

49 Hase T, Ueo T. Acetabular labral tear: arthroscopic diagnosis and treatment. Arthroscopy 1999;15:138-41

50 Elsaidi GA, Ruch DS, Schaefer WD, et al. Complications associated with traction on the hip during arthroscopy. J Bone Joint Surg [Br] 2004;86:793-8.

51 Byrd JWT. Hip arthroscopy in athletes. Instr Course Lect 2003;52:701-9.

\section{COMMENTARY}

Hip arthroscopy has evolved greatly in the last decade. Improvements in technology have made the procedure accessible and reproducible. This leads to more experience around the world and a larger number of surgeons performing the procedure, which allows further description of the pathology and a comparison of results between different institutions and even different countries. This means that hip arthroscopy has reached maturity and will only increase in the future. It is appropriate now to stop and review the hypothesis and results of previous studies and analyse what is still true and what has changed from the beginning. This paper adequately analyses hip arthroscopy from the point of view of the most common procedures and provides an understandable and expert discussion that serves both the orthopaedic surgeon willing to compromise on hip arthroscopy and the expert willing to evaluate his own experience and compare it with the evolution of literature on hip arthroscopy.

Victor M Ilizaliturri Jr National Rehabilitation Institute of Mexico, Mexico City, Mexico; vichip2002@yahoo.com.mx 